\title{
Preparation of Nanochitin/Polystyrene Composite Particles by Pickering Emulsion Polymerization Using Scaled-Down Chitin Nanofibers
}

\author{
Ryuta Watanabe, Kakeru Izaki, Kazuya Yamamoto and Jun-ichi Kadokawa *D \\ Graduate School of Science and Engineering, Kagoshima University, 1-21-40 Korimoto, \\ Kagoshima 890-0065, Japan; k0984020@kadai.jp (R.W.); k3320769@kadai.jp (K.I.); \\ yamamoto@eng.kagoshima-u.ac.jp (K.Y.) \\ * Correspondence: kadokawa@eng.kagoshima-u.ac.jp; Tel.: +81-99-285-7743
}

check for

updates

Citation: Watanabe, R.; Izaki, K.;

Yamamoto, K.; Kadokawa, J.-i.

Preparation of Nanochitin/

Polystyrene Composite Particles by

Pickering Emulsion Polymerization

Using Scaled-Down Chitin

Nanofibers. Coatings 2021, 11, 672.

https: / / doi.org/10.3390/

coatings11060672

Academic Editor: Philippe Evon

Received: 20 May 2021

Accepted: 31 May 2021

Published: 1 June 2021

Publisher's Note: MDPI stays neutral with regard to jurisdictional claims in published maps and institutional affiliations.

\begin{abstract}
In this study, we investigate the Pickering emulsion polymerization of styrene using scaleddown chitin nanofibers (SD-ChNFs) as stabilizers to produce nanochitin/polystyrene composite particles. Prior to emulsion polymerization, an SD-ChNF aqueous dispersion was prepared by disintegrating bundles of the parent ChNFs with an upper hierarchical scale in aqueous acetic acid through ultrasonication. After styrene was added to the resulting dispersions, the mixtures at the desired weight ratios (SD-ChNFs to styrene $=0.1: 1-1.4: 1$ ) were ultrasonicated to produce Pickering emulsions. Radical polymerization was then conducted in the presence of potassium persulfate as an initiator in the resulting emulsions to fabricate the composite particles. The results show that their average diameters decreased to a minimum of $84 \mathrm{~nm}$ as the weight ratios of SD-ChNFs to styrene increased. The IR and ${ }^{1} \mathrm{H}-\mathrm{NMR}$ spectra of the composite particle supported the presence of both chitin and polystyrene in the material.
\end{abstract}

Keywords: chitin nanofiber; composite particle; Pickering emulsion polymerization; polystyrene; scaled-down

\section{Introduction}

Chitin is one of the most abundant polysaccharides and acts as a structural material in biological systems. It has a regular structure consisting of $\beta(1 \rightarrow 4)$-linked repeating units of $N$-acetyl D-glucosamine [1-3]. It remains an unutilized biomass resource, principally because of its intractable bulk structure and insolubility in water and common organic solvents. An efficient approach to the functional materialization of chitin is nanofibrillation, that is, the fabrication of nanocrystals and nanofibers [4-10] because of the exceptional properties of bio-based nanomaterials, such as their lightweight character, high tensile strength, low thermal expansion coefficient, biocompatibility, and nanosheet formability for sensing and electronic devices [11-17]. We previously developed a facile method for fabricating chitin nanofibers (ChNFs) with widths of approximately 20-60 nm based on a bottom-up approach where self-assembling regeneration from a chitin/ionic liquid (1-allyl3-methylimidazolium bromide (AMIMBr)) ion gel using methanol was achieved $[18,19]$. This was based on our finding that AMIMBr efficiently dissolves and swells chitin [20]. Filtration of the resulting $\mathrm{ChNF}$ /methanol dispersion resulted in a film with a highly entangled nanofiber morphology.

We also previously reported styrene-in-water Pickering emulsion polymerization using self-assembled ChNFs as stabilizers to fabricate ChNF/polystyrene composite particles $[21,22]$. The stabilizers were additionally modified by anionic maleyl groups to provide amphiphilicity and simultaneously enhance dispersibility in aqueous media. Pickering emulsions are emulsions of any type, either oil-in-water, water-in-oil, or even multiple types which are stabilized by solid particles or other solid materials. These replace surfactants in general emulsions $[23,24]$. Pickering emulsion polymerization using polymerizable 
hydrophobic substrates has proven to be a fascinating method for fabricating composite particles with well-defined morphologies [25]. In our system using maleylated ChNFs as stabilizers, particle sizes were controllable, where the sizes gradually decreased with increasing weight ratios of ChNFs to styrene from 0.02:1 to 0.2:1; however, a further increase in the ChNF ratio could not be obtained to produce smaller particles because of the insufficient dispersibility of the ChNF stabilizer under these higher content conditions in aqueous media.

Nevertheless, we found that the self-assembled ChNFs had a bundle-like structure and were constructed through the assembly of thinner fibrils [26]. Accordingly, the treatment of a ChNF film with aqueous sodium hydroxide for partial generation of amino groups on the chitin chains resulted in disentanglement of the bundles by cationization and electrostatic repulsion in $1.0 \mathrm{~mol} / \mathrm{L}$ aqueous acetic acid with ultrasonication. This enabled individual thin fibril materials called scaled-down ChNFs (SD-ChNFs) to be obtained $[27,28]$.

In the present study, we use SD-ChNFs as stabilizers for Pickering emulsion polymerization of styrene to fabricate composite particles (Figure 1). Due to their better dispersibility than the aforementioned maleylated ChNFs in aqueous media, nanochitin/polystyrene composite particles with smaller sizes could be obtained with a higher stabilizer content. As previous Pickering emulsion approaches for the fabrication of polystyrene particles have been conducted mostly using inorganic stabilizers such as $\mathrm{SiO}_{2}$ and $\mathrm{Fe}_{2} \mathrm{O}_{3}$ substrates [29-32], the present materials have an advantageous potential to be used in biological and medicinal applications owing to the biocompatibility of ChNFs.

(a)
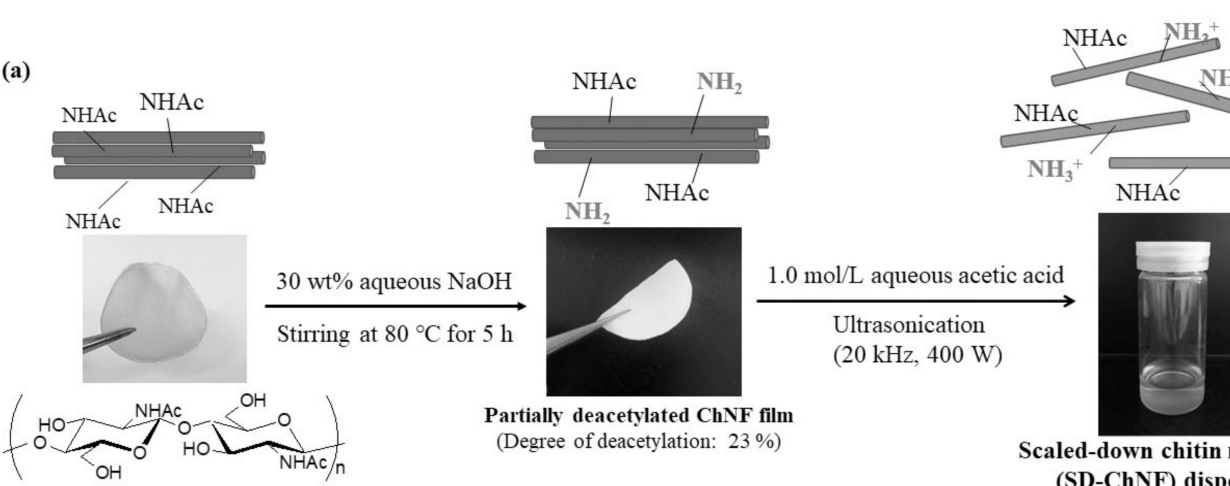

Chitin nanofiber (ChNF) film

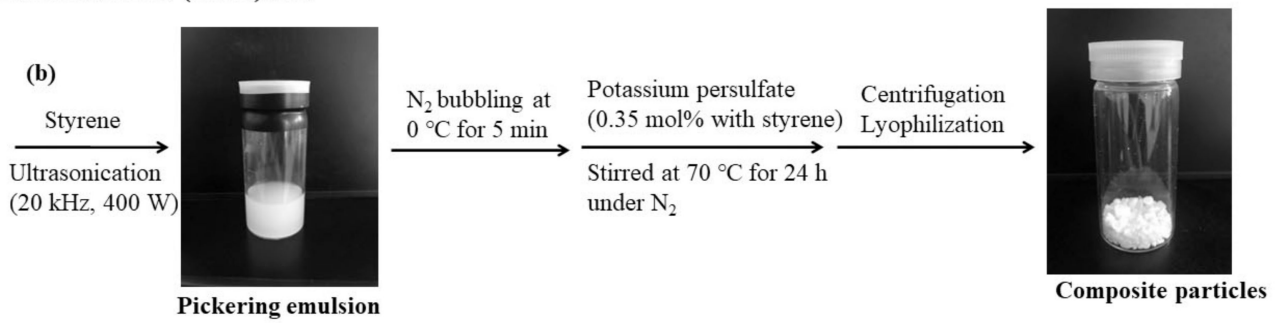

Figure 1. Procedures for the preparation of (a) a scaled-down chitin nanofiber (SD-ChNF) dispersion and (b) Pickering emulsion polymerization of styrene using SD-ChNFs as stabilizers.

\section{Materials and Methods}

\subsection{Materials}

Chitin powder from crab shells was purchased from Wako Pure Chemicals (Tokyo, Japan). An ionic liquid, AMIMBr, was prepared by the reaction of 1-methylimidazole with 3-bromo-1-propene according to a previously described method [33]. Other reagents and solvents were commercially available and used without further purification.

\subsection{Preparation of $S D$-ChNFs}

A mixture of chitin $(0.120 \mathrm{~g}, 0.590 \mathrm{mmol})$ with AMIMBr $(1.00 \mathrm{~g}, 4.92 \mathrm{mmol})$ was allowed to stand at room temperature for $24 \mathrm{~h}$ and subsequently heated with stirring at 
$80{ }^{\circ} \mathrm{C}$ for $24 \mathrm{~h}$ to obtain a chitin ion gel (10 wt\%). The gel was then soaked in methanol $(30 \mathrm{~mL})$ at room temperature for a week for regeneration, followed by ultrasonication (Branson 1510, 42 kHz, 70 W, Branson Ultrasonics Corporation, Brookfield, CT, USA) for $4 \mathrm{~h}$ to yield a self-assembled ChNF dispersion with methanol. The dispersion was subjected to filtration to isolate $\mathrm{ChNFs}$, and the isolated ChNFs were dried to obtain a ChNF film (0.117 g).

A mixture of the resulting film $(0.117 \mathrm{~g})$ with $30 \mathrm{wt} \%$ aqueous sodium hydroxide $(30.0 \mathrm{~mL})$ was heated at $80^{\circ} \mathrm{C}$ for $5 \mathrm{~h}$. The produced film was separated by filtration, washed with water and methanol, and dried to yield a partially deacetylated ChNF film $(0.0824 \mathrm{~g})$. From the integrated ratio of the signals assignable to acetamido protons to the signals assignable to anomeric (H1) protons in the ${ }^{1} \mathrm{H}-\mathrm{NMR}$ spectrum of the sample hydrolyzed from the produced partially deacetylated (PDA-) ChNF film in $\mathrm{DCl} / \mathrm{D}_{2} \mathrm{O}$, the degree of deacetylation (DDA) value was estimated to be $23.0 \%$.

A mixture of the partially deacetylated ChNF film with $1.0 \mathrm{~mol} / \mathrm{L}$ aqueous acetic acid $(10.0 \mathrm{~mL})$ was then ultrasonicated using a homogenizer (Branson Advanced-Digital Sonifier $450(20 \mathrm{kHz}, 400 \mathrm{~W})$, Branson Ultrasonics Corporation, Brookfield, CT, USA) at room temperature for $30 \mathrm{~min}$ to yield an aqueous dispersion of SD-ChNFs.

\subsection{Preparation of Nanochitin/Polystyrene Composite Particles}

The typical experimental procedure was the following (run 5 in Table 1$)$ : Styrene $(0.356 \mathrm{~g}$, $3.42 \mathrm{mmol}$ ) was added to the aqueous dispersion of SD-ChNFs (0.501 $\mathrm{g})$ and the mixture was ultrasonicated (Branson Advanced-Digital Sonifier $450(20 \mathrm{kHz}, 400 \mathrm{~W})$, Branson Ultrasonics Corporation, Brookfield, CT, USA) for $30 \mathrm{~min}$ to produce a Pickering emulsion. After $\mathrm{N}_{2}$ gas was bubbled into the emulsion for $5 \mathrm{~min}$ at $0{ }^{\circ} \mathrm{C}$, potassium persulfate $(2.80 \mathrm{mg}, 0.0104 \mathrm{mmol}$, $0.35 \mathrm{~mol} \%$ with styrene) was added. The resulting emulsified mixture was then kept at $70{ }^{\circ} \mathrm{C}$ for $24 \mathrm{~h}$ under stirring in a nitrogen atmosphere. The reaction mixture was centrifuged for $45 \mathrm{~min}$ at $3500 \mathrm{rpm}$, and the residual product was lyophilized to yield composite particles $(0.0657 \mathrm{~g})$. For scanning electron microscopy (SEM) measurement, a mixture of the product $(1.00 \mathrm{mg})$ and water $(10.0 \mathrm{~mL})$ was ultrasonicated for $1 \mathrm{~h}$ to yield a re-dispersion.

Table 1. Average diameters and yields of composite particles.

\begin{tabular}{ccccc}
\hline Run & $\begin{array}{c}\text { Weight Ratio } \\
\text { (SD-ChNFs to Styrene) }\end{array}$ & $\begin{array}{c}\text { Average Diameter } \\
(\mathbf{n m})\end{array}$ & $\begin{array}{c}\text { Standard } \\
\text { Deviation }\end{array}$ & Yield (mg) \\
\hline 1 & $0.1: 1$ & 259 & 24.1 & 32.5 \\
2 & $0.2: 1$ & 167 & 19.0 & 38.4 \\
3 & $0.4: 1$ & 130 & 8.40 & 45.2 \\
4 & $1: 1$ & 100 & 23.5 & 50.5 \\
5 & $1.4: 1$ & 84 & 11.8 & 65.7 \\
\hline
\end{tabular}

a Determined by SEM images.

\subsection{Measurements}

${ }^{1} \mathrm{H}-\mathrm{NMR}$ spectra were recorded using a JEOL ECX 400 spectrometer (JEOL, Akishima, Tokyo, Japan). Microscopic laser images were obtained using a Keyence VK-8500 laser microscope (Keyence, Osaka, Japan). SEM images were obtained using a Hitachi S-4100H electron microscope (Hitachi High-Technologies Corporation, Tokyo, Japan) with an accelerating voltage of $5 \mathrm{kV}$. IR spectra were recorded on a PerkinElmer Spectrum Two spectrometer (PerkinElmer Japan Co., Ltd., Yokohama, Japan).

\section{Results and Discussion}

Prior to performing Pickering emulsion polymerization, we prepared SD-ChNF dispersions in aqueous acetic acid according to a previously reported procedure as follows (Figure 1a) $[27,28]$. The self-assembled ChNF film was first fabricated by regeneration from the chitin/AMIMBr ion gel using methanol to produce the ChNF dispersion and subsequent filtration [18]. In Figure 2a, the SEM image of the ChNF/methanol dispersion shows the same nanoscale morphology as that reported in a previous study [18]. The film 
was then subjected to treatment with $30 \mathrm{wt} \%$ aqueous sodium hydroxide at $80{ }^{\circ} \mathrm{C}$ for $5 \mathrm{~h}$ to achieve partial deacetylation. A DDA value of $23 \%$ was estimated by ${ }^{1} \mathrm{H}-\mathrm{NMR}$ analysis after the acidic hydrolysis and dissolution in $\mathrm{DCl} / \mathrm{D}_{2} \mathrm{O}$. The produced film was mixed with $1.0 \mathrm{~mol} / \mathrm{L}$ aqueous acetic acid through ultrasonication using a homogenizer $(20 \mathrm{kHz}$, $400 \mathrm{~W})$ to produce the SD-ChNF/aqueous acetic acid dispersion. The sizes of the resulting nanochitin observed in the SEM image of the dispersion (Figure 2b) were clearly reduced as compared with those of the parent $\mathrm{ChNF} /$ methanol dispersion (Figure 2a), indicating the successful preparation of the desired SD-ChNF dispersion.
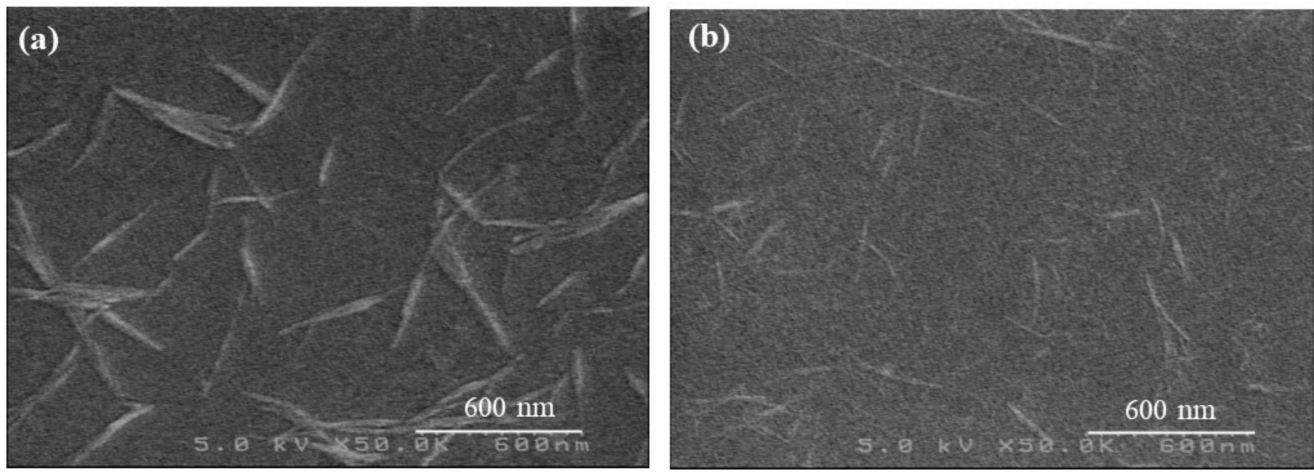

Figure 2. SEM images of the (a) parent $\mathrm{ChNF} /$ methanol dispersion and (b) SD-ChNF/aqueous acetic acid dispersion.

The Pickering emulsions were prepared by mixing styrene with the resulting dispersion (weight ratios of SD-ChNFs to styrene $=0.1: 1-1.4: 1$, runs 1-5 in Table 1)) (Figure 1b). The laser microscopic images of the obtained mixtures (images of Pickering emulsions of runs 1 and 5 are representatively shown in Figure 3) supported the adequate formation of the emulsions at all weight ratios, even at higher ChNF contents (runs 3-5) than those that did not induce the formation of clear emulsions using the maleylated ChNFs [21]. These results suggest the practice of scaling down the parent ChNFs into SD-ChNFs for improving dispersibility in aqueous media in order to effectively act as stabilizers in Pickering emulsions.
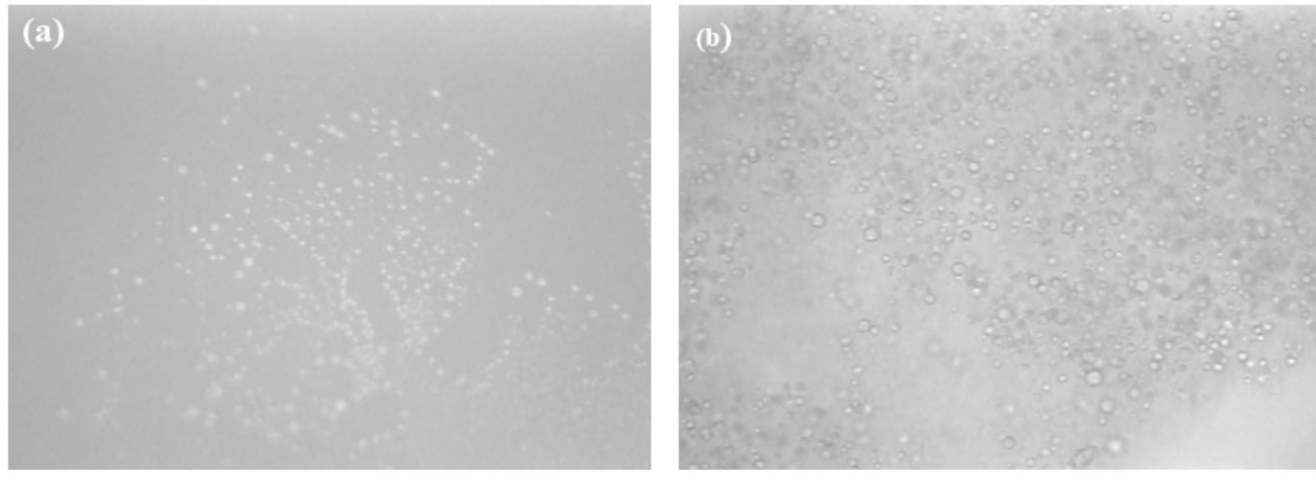

Figure 3. Microscopic laser images of Pickering emulsions for (a) run 1 and (b) run 5.

Pickering emulsion polymerization of styrene was then performed using the same procedure as that used for the maleylated ChNFs reported in our previous studies [21,22]. After nitrogen gas was bubbled into the emulsions, radical polymerization of styrene was conducted in the presence of potassium persulfate $(0.35 \mathrm{~mol} \%$ with styrene $)$ at $70{ }^{\circ} \mathrm{C}$ for $24 \mathrm{~h}$ while stirring in a nitrogen atmosphere (Figure $1 \mathrm{~b}$ ). The products were isolated by centrifugation and lyophilized to obtain SD-ChNF/polystyrene composite particles. The IR spectrum of the product (run 2, Figure 4c) exhibited characteristic absorptions from chitin at $3437 \mathrm{~cm}^{-1}(\mathrm{O}-\mathrm{H}), 1656$ and $1618 \mathrm{~cm}^{-1}(\mathrm{C}=\mathrm{O}$ of amide $\mathrm{I}), 1552 \mathrm{~cm}^{-1}(\mathrm{C}=\mathrm{O}$ of amide II), and $1072 \mathrm{~cm}^{-1}(\mathrm{C}-\mathrm{O}-\mathrm{C})$, as well as at $697 \mathrm{~cm}^{-1}$ for polystyrene (C-H of aromatic 
ring), respectively (Figure $4 a, b)$. The ${ }^{1} \mathrm{H}-\mathrm{NMR}$ spectrum of a solubilized fraction of the product of run 4 in $\mathrm{CDCl}_{3}$ is shown in Figure 5, where the observed signals are assignable to polystyrene, but the chitin component was not analyzed by NMR measurement due to its insolubility in common NMR solvents. These data indicate that the particles consisted of both chitin and polystyrene. After the products were re-dispersed in water, SEM images of the spin-coated samples from the re-dispersions were captured to evaluate the morphologies and sizes of the composite particles.

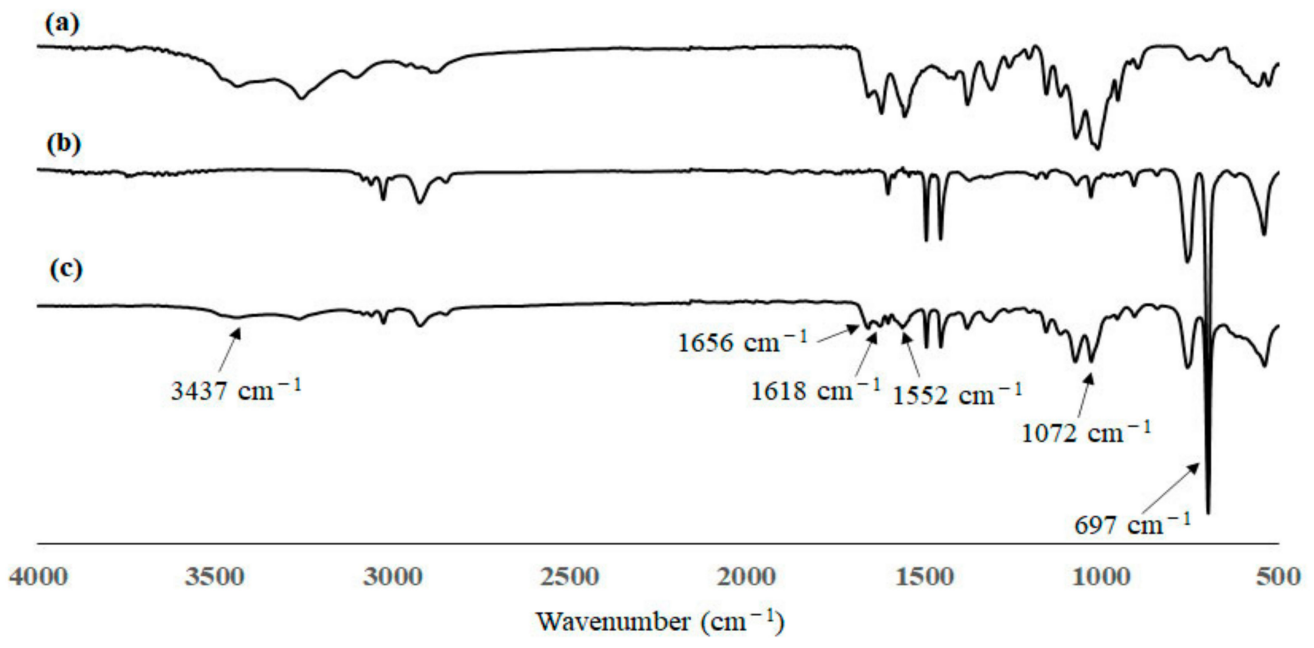

Figure 4. IR spectra of (a) the partially deacetylated (PDA-)ChNF film, (b) polystyrene, and (c) composite particles for run 2.

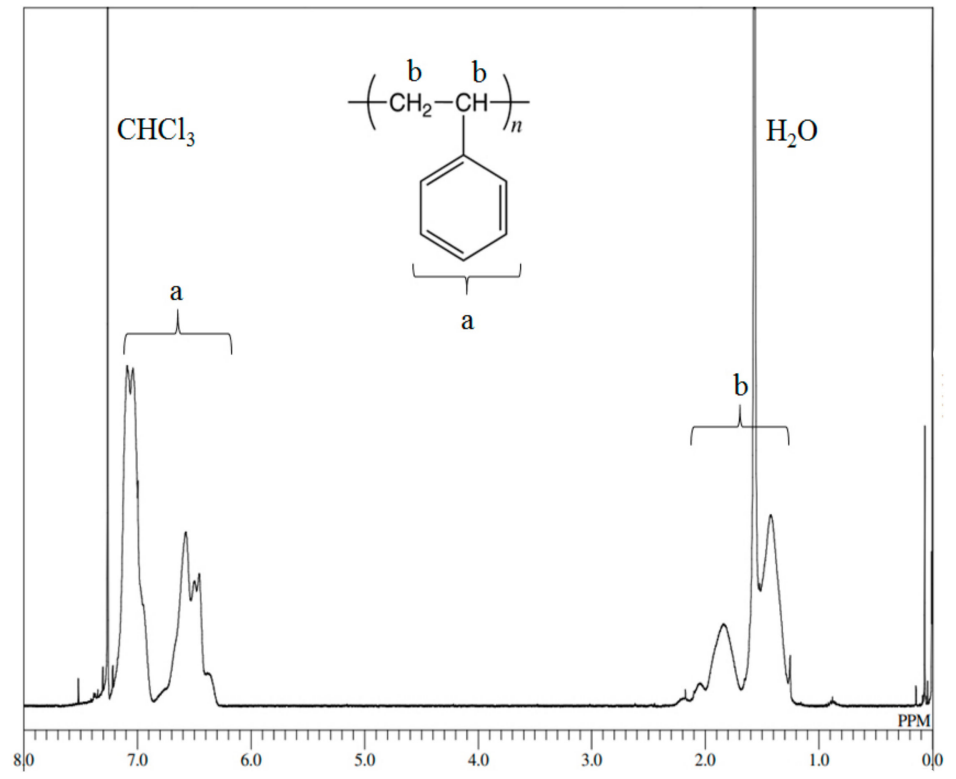

Figure 5. ${ }^{1} \mathrm{H}-\mathrm{NMR}$ spectrum of solubilized fraction of composite particles for run 4 in $\mathrm{CDCl}_{3}$.

The SEM images of the samples obtained using all the SD-ChNF/styrene weight ratios clearly show the particle morphologies (Figure 6). The particle sizes (average diameters) were calculated based on the vertical and horizontal lengths of 50 particles in each SEM image (Table 1). The standard deviation values for all the average diameters were relatively small, indicating the formation of composite particles with uniform sizes in all cases. The average diameter of the particles obtained by the SD-ChNF/styrene weight ratio of 0.1:1 (run 1) was comparable to that obtained by the same weight ratio of the maleylated ChNFs with an upper hierarchical scale as reported in our previous study (259 and $266 \mathrm{~nm}$, respectively) [21]; however, at a higher weight ratio (0.2:1, run 2), the average diameter of 
the particles using the SD-ChNFs was smaller than that using the maleylated ChNFs (167 and $199 \mathrm{~nm}$, respectively). Moreover, the average diameters were smaller with increasing $\mathrm{SD}-\mathrm{ChNF}$ /styrene weight ratios and reached $84 \mathrm{~nm}$ with an $\mathrm{SD}-\mathrm{ChNF}$ /styrene weight ratio of 1.4:1. These results strongly indicate that the SD-ChNFs efficiently acted as stabilizers for the present Pickering emulsion polymerization to fabricate composite particles that were smaller than $100 \mathrm{~nm}$. The weight yields of composite particles increased when increasing the SD-ChNF/styrene weigh ratios, indicating the formation of more stable emulsions in accordance with increased SD-ChNF ratios.
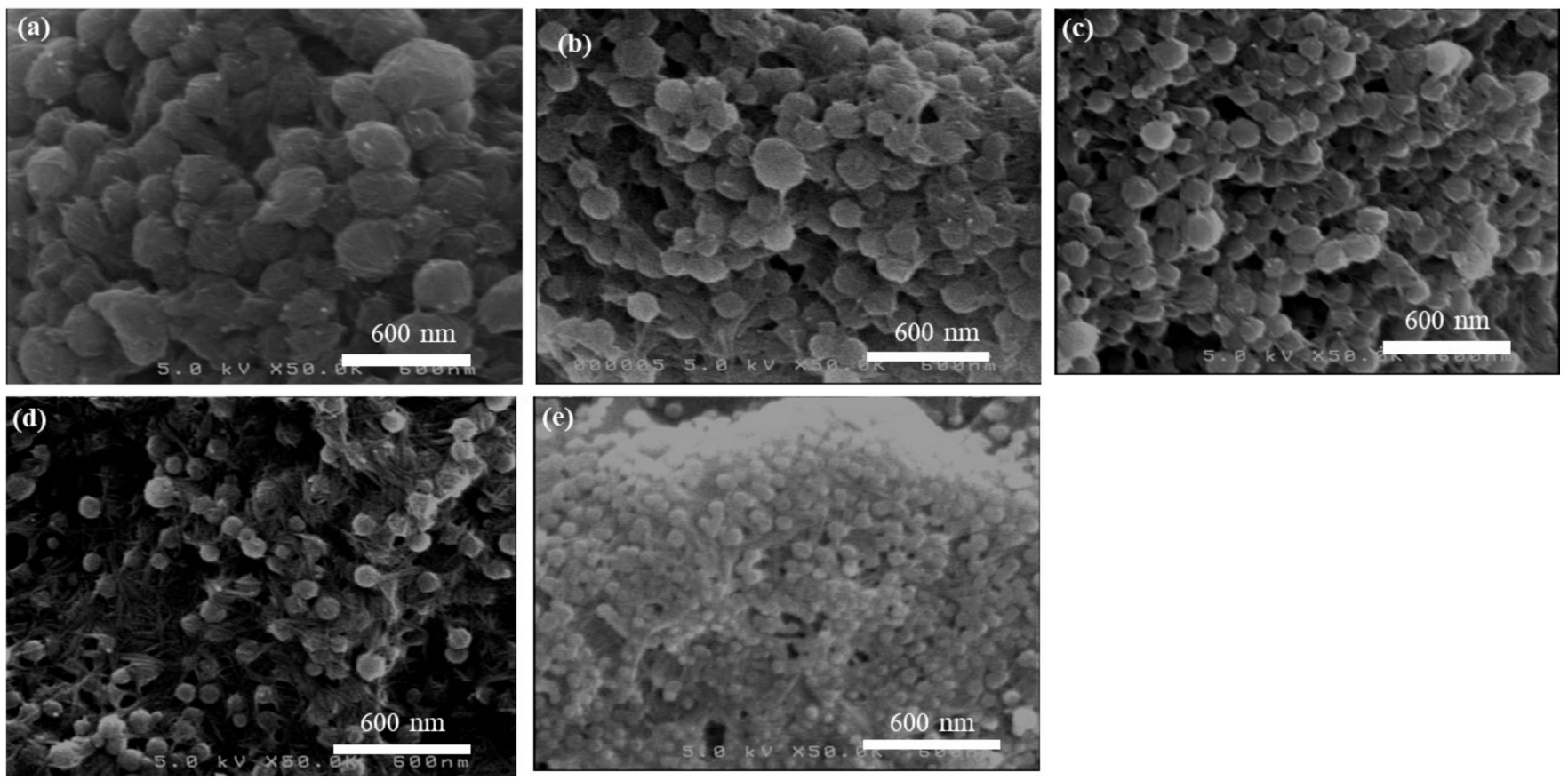

Figure 6. SEM images of SD-ChNF/polystyrene composite particles for (a-e) runs 1-5.

\section{Conclusions}

This study has investigated the Pickering emulsion polymerization of styrene using $\mathrm{SD}-\mathrm{ChNFs}$ as stabilizers to fabricate nanochitin/polystyrene composite particles. The SD-ChNFs used as stabilizers efficiently formed Pickering emulsions with styrene in aqueous acetic acid, even under higher weight ratios of SD-ChNFs to styrene (e.g., 1.4:1). Radical polymerization of styrene in the resulting emulsions was then conducted in the presence of a radical initiator to fabricate the desired composite particles. Their average diameters decreased with increasing weight ratios of SD-ChNFs to styrene to a minimum of $84 \mathrm{~nm}$. The resulting nanochitin/polystyrene composite particles can be converted into hollow particles composed of nanochitin/polystyrene shells by dissolving the inner polystyrene. The obtained materials have potential to be used as carriers for the controlled release of hydrophobic medical drugs owing to their biocompatibility and hydrophobicity, respectively. In the future, the approach described in this study will be employed in Pickering emulsions using other monomers to obtain nanochitin-based composite particles with functional polymers such as biodegradable and biocompatible polymers.

Author Contributions: J.-i.K. and K.Y. contributed to the methodology and writing of the paper. R.W. and K.I. performed the experiments and analysis. All authors have read and agreed to the published version of the manuscript.

Funding: This research received no external funding.

Institutional Review Board Statement: Not applicable.

Informed Consent Statement: Not applicable. 
Data Availability Statement: Not applicable.

Acknowledgments: Not applicable.

Conflicts of Interest: The authors declare no conflict of interest.

\section{References}

1. Pillai, C.K.S.; Paul, W.; Sharma, C.P. Chitin and chitosan polymers: Chemistry, solubility and fiber formation. Prog. Polym. Sci. 2009, 34, 641-678. [CrossRef]

2. Rinaudo, M. Chitin and chitosan: Properties and applications. Prog. Polym. Sci. 2006, 31, 603-632. [CrossRef]

3. Kurita, K. Chitin and chitosan: Functional biopolymers from marine crustaceans. Mar. Biotechnol. 2006, 8, 203-226. [CrossRef] [PubMed]

4. Ifuku, S.; Nogi, M.; Abe, K.; Yoshioka, M.; Morimoto, M.; Saimoto, H.; Yano, H. Preparation of chitin nanofibers with a uniform width as $\alpha$-chitin from crab shells. Biomacromolecules 2009, 10, 1584-1588. [CrossRef]

5. Ifuku, S. Preparation of chitin nanofibers from crab shell and their applications. Kobunshi Ronbunshu 2012, 69, 460-467. [CrossRef]

6. Ifuku, S.; Saimoto, H. Chitin nanofibers: Preparations, modifications, and applications. Nanoscale 2012, 4, 3308-3318. [CrossRef]

7. Ifuku, S. Chitin and chitosan nanofibers: Preparation and chemical modifications. Molecules 2014, 19, 18367-18380. [CrossRef]

8. Muzzarelli, R.A.A.; El Mehtedi, M.; Mattioli-Belmonte, M. Emerging biomedical applications of nano-chitins and nano-chitosans obtained via advanced eco-friendly technologies from marine resources. Mar. Drugs 2014, 12, 5468-5502. [CrossRef]

9. Rolandi, M.; Rolandi, R. Self-assembled chitin nanofibers and applications. Adv. Colloid Interface sci. 2014, 207, 216-222. [CrossRef]

10. Zhang, X.; Rolandi, M. Engineering strategies for chitin nanofibers. J. Mater. Chem. B 2017, 5, 2547-2559. [CrossRef] [PubMed]

11. You, J.; Li, M.; Ding, B.; Wu, X.; Li, C. Crab chitin-based 2D soft nanomaterials for fully biobased electric devices. Adv. Mater. 2017, 29, 1606895. [CrossRef] [PubMed]

12. Anraku, M.; Tabuchi, R.; Ifuku, S.; Nagae, T.; Iohara, D.; Tomida, H.; Uekama, K.; Maruyama, T.; Miyamura, S.; Hirayama, F.; et al An oral absorbent, surface-deacetylated chitin nano-fiber ameliorates renal injury and oxidative stress in 5/6 nephrectomized rats. Carbohydr. Polym. 2017, 161, 21-25. [CrossRef] [PubMed]

13. Koizumi, R.; Azuma, K.; Izawa, H.; Morimoto, M.; Ochi, K.; Tsuka, T.; Imagawa, T.; Osaki, T.; Ito, N.; Okamoto, Y.; et al. Oral administration of surface-deacetylated chitin nanofibers and chitosan inhibit 5-fluorouracil-induced intestinal mucositis in mice. Int. J. Mol. Sci. 2017, 18, 11. [CrossRef]

14. Satam, C.C.; Irvin, C.W.; Lang, A.W.; Jallorina, J.C.R.; Shofner, M.L.; Reynolds, J.R.; Meredith, J.C. Spray-Coated Multilayer Cellulose Nanocrystal-Chitin Nanofiber Films for Barrier Applications. ACS Sustain. Chem. Eng. 2018, 6, 10637-10644. [CrossRef]

15. Mushi, N.E.; Nishino, T.; Berglund, L.A.; Zhou, Q. Strong and Tough Chitin Film from $\alpha$-Chitin Nanofibers Prepared by High Pressure Homogenization and Chitosan Addition. ACS Sustain. Chem. Eng. 2019, 7, 1692-1697. [CrossRef]

16. Naghdi, T.; Golmohammadi, H.; Yousefi, H.; Hosseinifard, M.; Kostiv, U.; Horák, D.; Merkoçi, A. Chitin Nanofiber Paper toward Optical (Bio)sensing Applications. ACS Appl. Mater. Interfaces 2020, 12, 15538-15552. [CrossRef]

17. Sharma, P.R.; Sharma, S.K.; Lindström, T.; Hsiao, B.S. Water Purification: Nanocellulose-Enabled Membranes for Water Purification: Perspectives (Adv. Sustainable Syst. 5/2020). Adv. Sustain. Syst. 2020, 4, 2070009. [CrossRef]

18. Kadokawa, J.; Takegawa, A.; Mine, S.; Prasad, K. Preparation of chitin nanowhiskers using an ionic liquid and their composite materials with poly(vinyl alcohol). Carbohydr. Polym. 2011, 84, 1408-1412. [CrossRef]

19. Tajiri, R.; Setoguchi, T.; Wakizono, S.; Yamamoto, K.; Kadokawa, J. Preparation of self-assembled chitin nanofibers by regeneration from ion gels using calcium halide · dihydrate/methanol solutions. J. Biobased Mater. Bioenergy 2013, 7, 655-659. [CrossRef]

20. Prasad, K.; Murakami, M.; Kaneko, Y.; Takada, A.; Nakamura, Y.; Kadokawa, J. Weak gel of chitin with ionic liquid, 1-allyl-3methylimidazolium bromide. Int. J. Biol. Macromol. 2009, 45, 221-225. [CrossRef]

21. Noguchi, S.; Sato, K.; Yamamoto, K.; Kadokawa, J.I. Preparation of composite and hollow particles from self-assembled chitin nanofibers by Pickering emulsion polymerization. Int. J. Biol. Macromol. 2019, 126, 187-192. [CrossRef] [PubMed]

22. Noguchi, S.; Yamamoto, K.; Kadokawa, J.I. Preparation of chitin-based fluorescent hollow particles by Pickering emulsion polymerization using functional chitin nanofibers. Int. J. Biol. Macromol. 2020, 157, 680-686. [CrossRef] [PubMed]

23. Chevalier, Y.; Bolzinger, M.-A. Emulsions stabilized with solid nanoparticles: Pickering emulsions. Colloid. Surf. A 2013, 439, 23-34. [CrossRef]

24. Yang, Y.; Fang, Z.; Chen, X.; Zhang, W.; Xie, Y.; Chen, Y.; Liu, Z.; Yuan, W. An Overview of Pickering Emulsions: Solid-Particle Materials, Classification, Morphology, and Applications. Front. Pharm. 2017, 8, 287. [CrossRef]

25. Bon, S.A.F. Pickering Emulsion Polymerization. In Encyclopedia of Polymeric Nanomaterials; Kobayashi, S., Müllen, K., Eds.; Springer: Berlin/Heidelberg, Germany, 2014; pp. 1-6.

26. Kadokawa, J.; Kawano, A.; Yamamoto, K. Fabrication of semi-crystalline film by hexanoylation on self-assembled chitin nanofibers. ChemistrySelect 2019, 4, 797-801. [CrossRef]

27. Hashiguchi, T.; Yamamoto, K.; Kadokawa, J. Preparation of soft materials by scaling down self-assembled chitin nanofibers. In Proceedings of the 101st CSJ Annual Meeting, Online, 19-22 March 2021.

28. Hashiguchi, T.; Yamamoto, K.; Kadokawa, J. Fabrication of highly flexible nanochitin film and its composite film with anionic polysaccharide. Carbohydr. Polym. 2021. submitted. 
29. Zhang, K.; Wu, W.; Meng, H.; Guo, K.; Chen, J.F. Pickering emulsion polymerization: Preparation of polystyrene/nano-SiO2 composite microspheres with core-shell structure. Powder Technol. 2009, 190, 393-400. [CrossRef]

30. Zhou, H.; Shi, T.; Zhou, X. Preparation of polystyrene $/ \mathrm{SiO}_{2}$ microsphere via Pickering emulsion polymerization: Synergistic effect of $\mathrm{SiO} 2$ concentrations and initiator sorts. Appl. Surf. Sci. 2013, 266, 33-38. [CrossRef]

31. Kim, Y.J.; Liu, Y.D.; Seo, Y.; Choi, H.J. Pickering-Emulsion-Polymerized Polystyrene $/ \mathrm{Fe}_{2} \mathrm{O}_{3}$ Composite Particles and Their Magnetoresponsive Characteristics. Langmuir 2013, 29, 4959-4965. [CrossRef] [PubMed]

32. Kim, S.D.; Zhang, W.L.; Choi, H.J. Pickering emulsion-fabricated polystyrene-graphene oxide microspheres and their electrorheology. J. Mater. Chem. C 2014, 2, 7541-7546. [CrossRef]

33. Zhao, D.B.; Fei, Z.F.; Geldbach, T.J.; Scopelliti, R.; Laurenczy, G.; Dyson, P.J. Allyl-functionalised ionic liquids: Synthesis, characterisation, and reactivity. Helv. Chim. Acta 2005, 88, 665-675. [CrossRef] 